\title{
Article \\ Conceptual Classification of Leading Indicators for the Dynamic Analysis of Emerging Risks in Integrated Management Systems
}

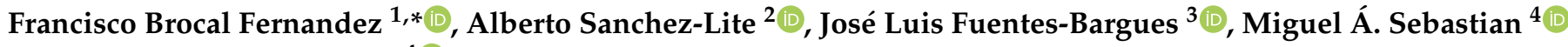 \\ and Cristina González-Gaya ${ }^{4}[\mathbb{C}$
}

1 Department of Physics, Systems Engineering and Signal Theory, Universidad de Alicante, 03690 Alicante, Spain

2 Department of Materials Science and Metallurgical Engineering, Graphic Expression in Engineering, Cartographic Engineering, Geodesy and Photogrammetry, Mechanical Engineering and Manufacturing Engineering, Universidad de Valladolid, 47004 Valladolid, Spain; asanchez@eii.uva.es

3 PRINS Research Center, Universitat Politècnica de València, Camino de Vera s/n, 46022 València, Spain; jofuebar@dpi.upv.es

4 Department of Manufacturing Engineering, Universidad Nacional de Educación a Distancia (UNED), 28015 Madrid, Spain; msebastian@ind.uned.es (M.Á.S.); cggaya@ind.uned.es (C.G.-G.)

* Correspondence: francisco.brocal@ua.es

Citation: Brocal Fernandez, F.; Sanchez-Lite, A.; Fuentes-Bargues, J.L.; Sebastian, M.Á.; González-Gaya, C. Conceptual Classification of Leading Indicators for the Dynamic Analysis of Emerging Risks in Integrated Management Systems. Appl. Sci. 2021, 11, 10921. https:// doi.org/10.3390/app112210921

Academic Editors:

Álvaro Rodríguez-Prieto and Francisco Javier Trujillo Vilches

Received: 25 October 2021

Accepted: 13 November 2021

Published: 18 November 2021

Publisher's Note: MDPI stays neutral with regard to jurisdictional claims in published maps and institutional affiliations.

Copyright: (c) 2021 by the authors Licensee MDPI, Basel, Switzerland. This article is an open access article distributed under the terms and conditions of the Creative Commons Attribution (CC BY) license (https:// creativecommons.org/licenses/by/ $4.0 /)$

\begin{abstract}
Companies that implement Integrated Management Systems (IMS) require approaches that optimize resources and results. In the case of IMS of a new or emerging nature, the use of dynamics risk analysis approaches and the integration of real-time monitoring data in the risk assessment process offers news perspectives. The objective of this work is to identify and classify leading indicators that facilitate the dynamic analyses of emerging risks in an IMS for quality, environment, and safety. For it, such indicator analysis has been based on a bibliographic analysis. Regarding results, firstly, a structure of indicators emerges configured of three categories organized in two levels. At the first level, it is established by the indicators of the IMS which can be integrated. The second level is configured of two categories of interrelated indicators, that is, process integrity indicators and occupational risks indicators. In turn, each of these three categories has two dimensions. The first dimension represents the direction of the indicator, leading or lagging indicator. The second dimension represents the risk nature, emerging or traditional risk. Secondly, a classification of the leading indicators is derived according to the categories of the indicators and the risk nature. This classification shows the direction of the leading indicators as well as qualitative graduation of the potential associated consequences. Said theoretical framework has been applied to a case study configured by a manufacturing process. Thus, a conceptual scheme has been developed that represents the first step towards a more in-depth and detailed development that allows the identification and definition of specific leading indicators within an IMS from a dynamic and emerging risk perspective.
\end{abstract}

Keywords: dynamics risk analysis; emerging risk; integrated management systems; leading indicators; safety

\section{Introduction}

Companies that adopt multiple management systems require integrated approaches that optimize resources and results. There is a tendency to implement Integrated Management Systems (IMS) covering Occupational Health \& Safety (OH\&S), Environmental and Quality through the ISO 45001 (or OSHAS, 18001), ISO 14001, and ISO 9001, respectively [1].

In the specific case of the risk management field linked to industrial safety three groups of management systems can be defined [2]: Systems that address risk from a general and/or systemic perspective; Systems that deal with accident risk management. In this case, the 
risk of an occupational accident and a major accident can be differentiated; and Systems that address the emerging risk. In the case of risk management systems of a new or emerging nature, the use of dynamics risk analysis approaches and the integration of real-time monitoring data in the risk assessment process offers an optimization opportunity [3].

Such monitoring process should be integrated into the iterative process PDVA (Plan, Do, Verify, Act) used by organizations to achieve continual improvement [1], this process being the basis of the integration process of management systems [4]. This requires indicators that can be incorporated into the PDVA process from an integrative perspective. These indicators need proactive approaches, especially when risks are emerging given their dynamic characteristics. In general, leading indicators can control risk (proactivity), while lagging indicators simply can report their increase after an unwanted event has occurred (reactivity) [5]. In a safety management context is necessary a continuous focus on lagging indicators of past outcomes, including deficiencies and incidents, and leading indicators of technical, organizational, and human functions that drive safety forward [6].

In this way, the main objective of this work is to identify and classify leading indicators that facilitate the dynamic analyses of emerging risks in an integrated management system for quality, environment, and safety.

The structure of this paper is as follows: firstly, an analysis of the indicators has been carried out through a literature review. This analysis has been structured considering the specific areas of safety management, occupational safety, process safety, and approaches to the development of safety/risk indicators. Secondly, the classification of leading indicators has been proposed based on the previous results. Thirdly, said theoretical framework has been applied to a case study configured by a manufacturing process. Finally, such results have been analyzed and discussed.

\section{Analysis of Indicators}

The indicator analysis carried out in this section is initially based on an analysis of the theoretical framework proposed in [7], the dynamic risk analysis methods considered in $[8,9]$, and the proactive indicators suggested in $[5,10,11]$ in the context of the integration of management systems [4]. This analysis has been complemented by a review of the literature in the Web of Science. The search criteria used was the shown in Table 1. The low number of results obtained especially with the combinations 3-7 shows the limited published research on this topic to date.

Table 1. Keywords used for the search (Results from the Web of Science; Field tag: topic; All Databases; All years).

\begin{tabular}{|c|c|c|c|}
\hline & \multirow{2}{*}{ Keywords Used for the Search } & \multicolumn{2}{|c|}{ Number of Results } \\
\hline & & All Years & Last 5 Years \\
\hline 1 & $\begin{array}{c}((\mathrm{TS}=(\text { leading indicators })) \text { AND TS }=(\text { safety })) \text { AND TS }= \\
\quad \text { (integrated management system })\end{array}$ & 99 & 49 \\
\hline 2 & $\begin{array}{c}((\mathrm{TS}=(\text { leading indicators })) \text { AND TS }=(\text { management } \\
\text { system })) \text { AND TS }=(\text { emerging risk })\end{array}$ & 86 & 43 \\
\hline 3 & $\begin{array}{c}(((\mathrm{TS}=(\text { leading indicators })) \text { AND TS }=(\text { "management } \\
\text { system") }) \text { AND TS = }(\text { dynamic analysis })) \text { AND TS = (risk })\end{array}$ & 5 & 4 \\
\hline 4 & $\begin{array}{c}((\mathrm{TS}=(\text { leading indicators })) \text { AND TS }=(\text { occupational risk })) \\
\text { AND TS }=(\text { integrated management system })\end{array}$ & 13 & 8 \\
\hline 5 & $\begin{array}{c}((\mathrm{TS}=(\text { leading indicators })) \text { AND TS = (occupational } \\
\text { accident })) \text { AND TS = (integrated management system })\end{array}$ & 6 & 4 \\
\hline 6 & $\begin{array}{c}((\mathrm{TS}=(\text { leading indicators })) \text { AND TS }=(\text { major accident })) \\
\text { AND TS }=(\text { integrated management system })\end{array}$ & 3 & 2 \\
\hline 7 & $\begin{array}{l}((\mathrm{TS}=\text { (leading indicators })) \text { AND TS }=\text { (integrated } \\
\text { management system })) \text { AND TS = (emerging risk })\end{array}$ & 20 & 10 \\
\hline
\end{tabular}




\subsection{Safety Management}

The literature, scientific y professional was reviewed in [12], in matter de process safety indicators, distinguish between leading and lagging indicators as well as between process safety, management and organization and, occupational indicators. In the professional literature, indicators for safety and process safety have mainly three functional characteristics regarding scientific literature, being descriptive, monitoring, and comparing between companies. Regarding the differences between indicators for management and organization in the two literature sources are less marked. A Bayesian Belief Net has been proposed in [13] that shows within a safety management system dependency between process integrity indicators and occupational risks indicators. Tables 2 and 3 show some examples of these two classifications of process safety indicators and management and organization indicators. Thus, both common and specific indicators can be observed for the scientific and professional literature. In any case, the common indicators are the most frequent in both classifications.

Table 2. Examples of process safety indicators from the scientific and professional literature (Adapted from [12]).

\begin{tabular}{|c|c|c|}
\hline \multirow{2}{*}{ Examples } & \multicolumn{2}{|c|}{ Process Safety Indicators } \\
\hline & Scientific Literature & Professional Literature \\
\hline Alarms, failures, numbers per time period & - & - \\
\hline Exposure to dangerous substances/activities & $\bullet$ & $\bullet$ \\
\hline Fires, explosions, number, costs & $\bullet$ & - \\
\hline Process design, failures, maintenance, quality control, failures & $\bullet$ & $\bullet$ \\
\hline Safety system, frequency of activation & - & - \\
\hline Barriers quality & $\bullet$ & --- \\
\hline Process deviations, number & $\bullet$ & --- \\
\hline Safety system, frequency of failure & --- & • \\
\hline Process disturbances outside design envelop, number & -- & • \\
\hline Storage dangerous materials, amounts & --- & $\bullet$ \\
\hline
\end{tabular}

Table 3. Examples of management and organizational indicators from the scientific and professional literature (Adapted from [12]).

\begin{tabular}{|c|c|c|}
\hline \multirow{2}{*}{ Examples } & \multicolumn{2}{|c|}{ Management and Organisational Indicators } \\
\hline & Scientific Literature & Professional Literature \\
\hline Behavior, unsafe situations, positive feedback & $\bullet$ & $\bullet$ \\
\hline Safety management activities & $\bullet$ & $\bullet$ \\
\hline Safety culture, climate, index & $\bullet$ & $\bullet$ \\
\hline Audits, number performed, settled action points & $\bullet$ & $\bullet$ \\
\hline Inspections, number performed & $\bullet$ & $\bullet$ \\
\hline Safety commissions, settled action points & $\bullet$ & --- \\
\hline Decisions, safety arguments & $\bullet$ & -- \\
\hline Emergency procedures, correctness/availability & $-\cdots$ & $\bullet$ \\
\hline Hazard identification and risk analysis & -- & $\bullet$ \\
\hline Product safety & --- & $\bullet$ \\
\hline
\end{tabular}

Implement IMSs constitutes added value where some of the benefits are the improvement at the level of the coordinated and integrated management of the risk associated 
with the environment, quality of products, and OH\&S and company assets [14]. Some of the most positive points regarding the integration of MSs are task simplification (documentation, requirements) [15]. The next procedures are integrated into the IMS [15,16]: Planning, Internal audits, Management review, Control of nonconformities, Preventive and corrective action, Product realization, Resource management, Determination of requirements, Improvement, Document control, Record control, and Internal communication. These procedures are directly or indirectly linked to the indicators indicated in the previous tables.

The iterative process PDVA is the basis of the IMS [4]. The reason for the IMS process is based on the PDVA cycle is because it is a method of proven effectiveness and profitability, and because it facilitates the development of a systems integration project [4]. For example, the process for implementing the IMS for OH\&S and Environmental in the in an operating nuclear power plant in East China was formulated by using the PDVA cycle [17]. In the PDVA cycle the four main steps towards the implementation of an IMS can be depicted, supported by the Vision; Mission; Culture; Business objectives; Organizational roles, Responsibilities, and Authorities as well as the Management commitment and Leadership [14].

\subsection{Occupational Safety and Process Safety}

There is a possible overlap between these occupational safety and process safety indicators [12]. Regarding occupational safety, such authors considered some of its differentiating characteristics, such as those of containment and the size of the possible consequences. In any case minor, more frequent, accidents can provide information about the major accidents. In this sense, there are important links and transitional spaces between occupational accidents and major accidents, where, for example, comparing the definitions for both types of accidents, it could be said that a major accident could also be considered an occupational accident whenever there is harm to workers (injury and ill health) [18].

Some examples of indicators for occupational safety in the scientific literature are [12]: Near accidents, number; Accidents with/without lost days, number.

In the SMEs context, there are several OSH performance indicators regarding management and organization and regarding individual OSH [19]. Thus, such authors identified 14 management and organization indicators: personnel management policies; safety climate; certification in OSHMS; OSH policies; risk communication and information; organizational commitment; workers' involvement; management' involvement; investment/resources; risk assessment; accidents analysis; risk control; training (program and frequency); occupational accidents, diseases, and absenteeism. Regarding to individual OSH indicators, the following ones were identified risk perception; unsafe behaviors; attitudes; workers' motivation regarding OSH issues and satisfaction at work; age.

\subsection{Approaches to the Development of Safety/Risk Indicators}

The approaches to the development of safety/risk indicators can be classified into four classes whit to dynamic risk assessment through monitoring technical, human, and organizational factors (THO Factors) [5].

Thus, this classification has been graded according to the precision of the assessment of risk on a real-time basis. Thus, classes, I and II are characterized by a retrospective and predictive perspective, that is, lagging and leading perspective, respectively. Classes III and IV allow a more reliable evaluation of risk on a real-time basis.

Class I approaches are developed on the foundations of the effect of THO factors in past accidents, and correlation with the overall safety is assumed. Class II approaches are developed based on risk models for the potential accident scenarios addressed, and the connection to the overall risk level is logically supported by these models. This perspective has been integrated into the scheme about proactive approaches to assess organizational factors' effect on safety/risk proposed in [20]. The result of such integration is schematically shown in Figure 1. 


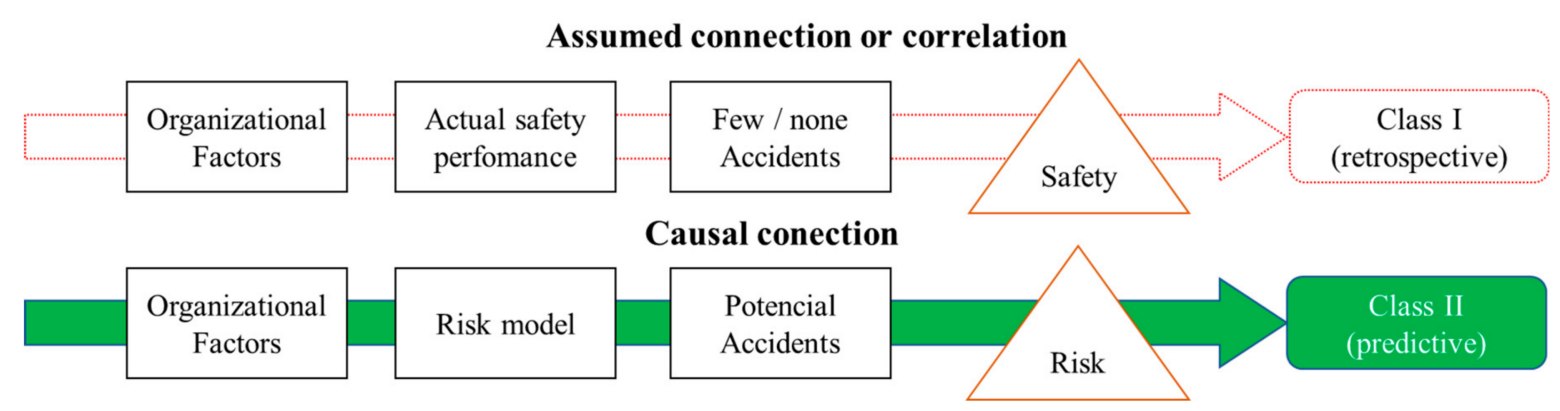

Figure 1. Proactive approaches to assess organizational factors' effect on safety/risk (Adapted from [5,20]).

Classes III and IV approaches assess accurately variations of the overall risk level through specific techniques aggregating the information provided by the indicators. Class III can be used Frequency update techniques and form class IV Frequency update techniques.

In Table 4, examples are shown on the classification of class I and II indicators or approaches for their development. In general, the classification criteria for class I are based on the degree of correlation with safety/risk is unknown, or when the relationship between the indicators and the risk level is unclear. On the other hand, the classification criteria for class II are based on the connection with safety/risk is known (class II).

Table 4. Examples of indicators Class I and II or approaches for their development (Adapted from [5]).

\begin{tabular}{|c|c|c|}
\hline \multirow{2}{*}{ Indicators or Approaches for Their Development } & \multicolumn{2}{|c|}{ Indicator Typology } \\
\hline & Class I & Class II \\
\hline United States Nuclear Regulatory Commission work & $\bullet$ & $\bullet$ \\
\hline Accident sequence precursor-based indicators & $\bullet$ & $\bullet$ \\
\hline Resilience-based early warning indicators & $\bullet$ & $\bullet$ \\
\hline Operator-specific safety indicators & $\bullet$ & $\bullet$ \\
\hline $\begin{array}{l}\text { Performance indicators defined by the World Association of } \\
\text { Nuclear Operators }\end{array}$ & $\bullet$ & -- \\
\hline Operational safety indicators & $\bullet$ & - \\
\hline Safety performance indicators & $\bullet$ & - \\
\hline Probabilistic indicators & - & $\bullet$ \\
\hline Probabilistic safety assessment-based risk indicators & - & $\bullet$ \\
\hline
\end{tabular}

Class III approaches based on frequency update techniques usually consider indicators describing factors as health, safety, environmental management, and other relevant issues affecting the baseline frequency value [21-24]. Some representative methods are considered in [5], such as the Center for Chemical Process Safety [21], American Petroleum Institute 581 [24], Management Assessment Guidelines in the Evaluation of Risk [22], Barrier method [25]. The risk barometer [26] is an example that may be classified as class IV that assesses the performance of safety barriers by means of specific sets of indicators and relates this to the overall risk picture for evaluation of possible risk fluctuation.

\section{Classification of Leading Indicators}

A schematic summary of the results shown in the previous sections could be the following: Two categories of indicators are considered in [13]: (i) process integrity indicators; (ii) and occupational risks indicators. Three categories of indicators are proposed in [12]: (i) management and organization indicators; (ii) process safety indicators; (iii) occupational safety indicators. And in the SMEs context [19] two categories on OSH performance indicators are identified: management and organization indicators; and individual OSH indicators. A pyramidal structure with four levels of process safety indicators is considered in [27]: Loss of Primary Containment (LOPC) Events of Greater Consequence; LOPC 
Events of Lesser Consequence; Challenges to Safety Systems; and Operating Discipline \& Management System Performance Indicators.

Considering the previous schematic summary in an integrated way, a structure of indicators emerges configured of three categories organized in two levels as shown in the Figure 2. Conceptually following to [27]: the categories occupational risks and process integrity are associated with an incident with greater consequence resulting from actual losses of containment and loss of primary containment events with a lesser consequence but may be predictive; category integrated management represent challenges to the safety systems and provides an opportunity to identify and correct weaknesses within the safety system.

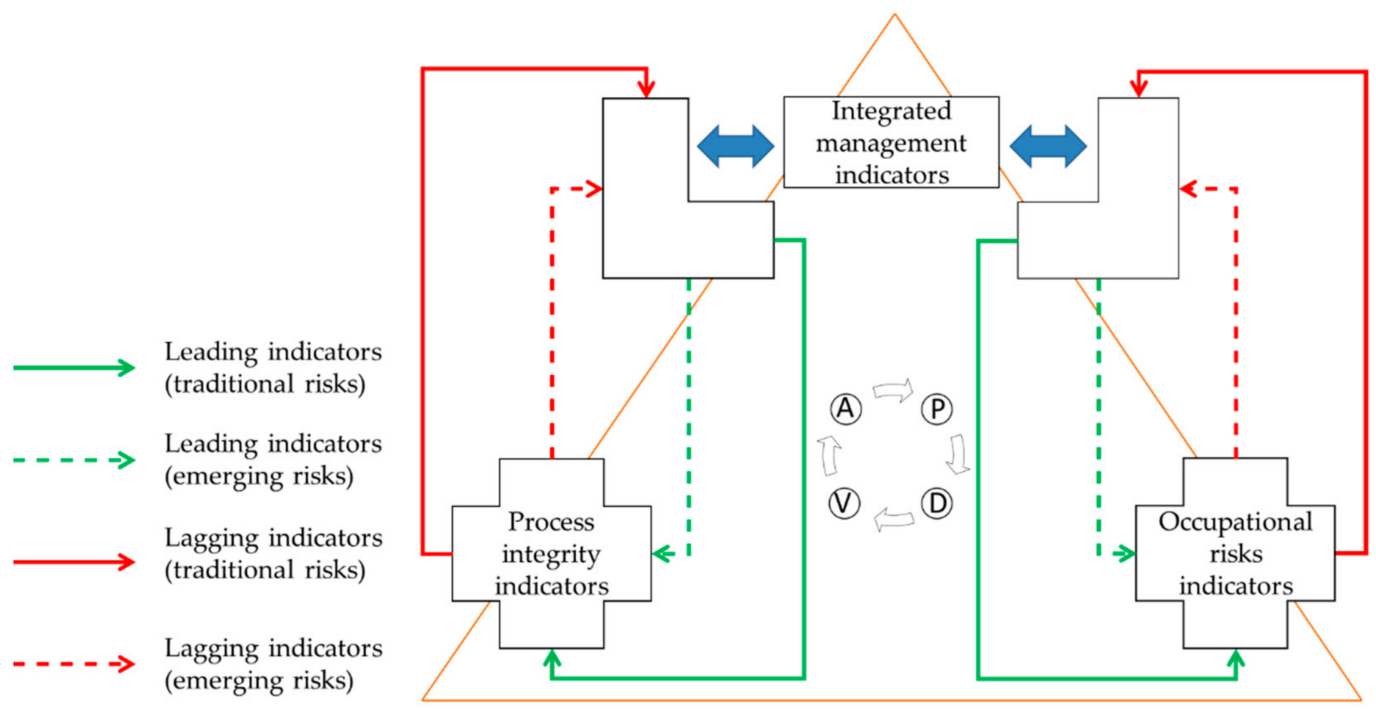

Figure 2. Integration of leading and lagging indicators in an IMS (Own elaboration).

At the first level of said structure, it is established by the indicators of the management system which can be integrated, as shown symbolically in the Figure 2. The second level is configured of two categories of interrelated indicators, that is, process integrity indicators and occupational risks indicators. In turn, each of these three categories has two dimensions. As for the first dimension, it represents the direction of the indicator, that is, leading or lagging indicator. Regarding the second dimension, the risk nature, that is, emerging or traditional risk, it can be determined by paying attention mainly to the consequence variable, according to the criteria exposed in $[7,28]$.

From all this, a classification of indicators as shown in the Figure 3 is derived. More specifically, a classification of leading indicators also is derived as shown in the Table 5. This table shows the direction of the leading indicators as well as qualitative graduation of the potential associated consequences, following the concept considered in [27]. These consequences have been graded with greater intensity when the risk is an emerging risk.

Table 5. Classification of leading indicators (Own elaboration).

\begin{tabular}{|c|c|c|c|c|c|c|}
\hline & \multicolumn{3}{|c|}{ Emerging Risk } & \multicolumn{3}{|c|}{ Traditional Risks } \\
\hline & $\begin{array}{l}\text { Occupational. } \\
\text { Risks }\end{array}$ & $\begin{array}{l}\text { Process } \\
\text { Integrity }\end{array}$ & $\begin{array}{c}\text { Integrated } \\
\text { Management }\end{array}$ & $\begin{array}{c}\text { Occupational. } \\
\text { Risks }\end{array}$ & $\begin{array}{l}\text { Process } \\
\text { Integrity }\end{array}$ & $\begin{array}{c}\text { Integrated } \\
\text { Management }\end{array}$ \\
\hline $\begin{array}{l}\text { Leading } \\
\text { indicators }\end{array}$ & & & & 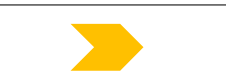 & 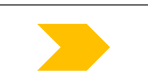 & \\
\hline
\end{tabular}




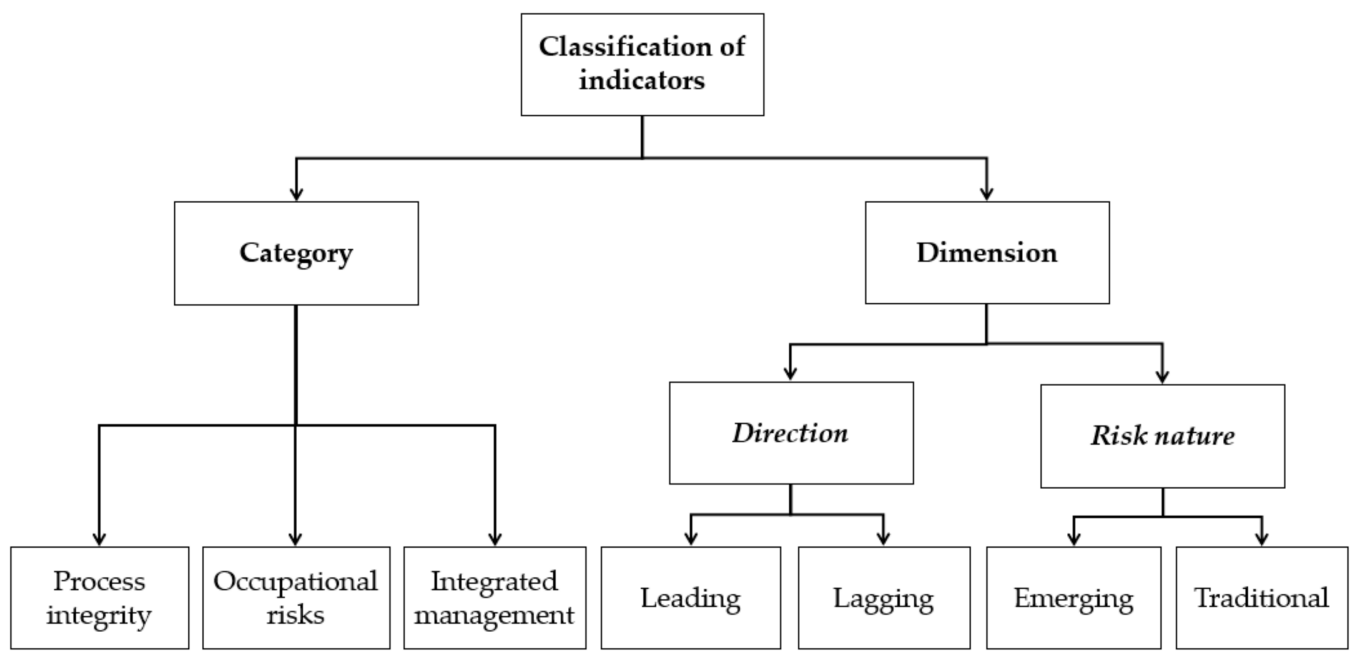

Figure 3. Classification of indicators (Own elaboration).

\section{Case Study}

The case study presented below is based on a generic and theoretical manufacturing process. The objective of this is to show in a schematic way the applicability of the theoretical framework configured by the classification of leading indicators defined in the previous section.

Thus, the manufacturing process that is the object of this case study is part of an integrated management system and is characterized by a high level of automation, as well as the use of nanomaterials as one of the components of the raw material.

The study of automated manufacturing processes, as well as the use of nanomaterials from an emerging risk management perspective, has been addressed by [7]. These authors consider that industrial automation and exposure to nanomaterials generate emerging risks with the potential, in both cases, of generating high consequences for safety and health.

From the perspective of this work, the risk of exposure to nanoparticles is mainly related to occupational risk, and the risks derived from automation are related to process integrity. However, the risk management of both types of risks could be integrated, especially considering the relationship between both types of risks according to the approach [18].

Thus, this case study has been adapted to the structure defined in the previous section, as shown in Table 6. In this way, three categories of indicators have been defined (occupational risk, process integrity, and integrated management), considering the two proposed dimensions, that is, direction and nature of risk. In terms of direction, both types, leading and lagging indicators, have been considered. Regarding the nature of the risk, the emergent risk has been considered, according to the objective of this work.

Table 6. Case study (Own elaboration).

\begin{tabular}{lccc}
\hline & \multicolumn{3}{c}{ Emerging Risk } \\
\cline { 2 - 4 } & Occupational Risks & Process Integrity & $\begin{array}{c}\text { Integrated } \\
\text { Management }\end{array}$ \\
\hline Leading indicators & $\begin{array}{c}\text { Percent of } \\
\text { nanomaterial } \\
\text { environmental } \\
\text { concentration within } \\
\text { specifications }\end{array}$ & $\begin{array}{c}\text { Percent of safety } \\
\text { critical equipment } \\
\text { within specifications }\end{array}$ & $\begin{array}{c}\text { Percentage of risks } \\
\text { within specifications }\end{array}$ \\
\hline Lagging indicators & $\begin{array}{c}\text { Number of times the } \\
\text { limit value is } \\
\text { exceeded }\end{array}$ & $\begin{array}{c}\text { Number of failures of } \\
\text { safety critical } \\
\text { equipment }\end{array}$ & $\begin{array}{c}\text { Percentage of risks } \\
\text { that exceed } \\
\text { specifications }\end{array}$ \\
\hline
\end{tabular}


Regarding the criteria used for the design of the indicators shown in the table, the following have been used: the leading indicators for occupational risks and process integrity have been defined by [29]. As for the leading indicators for integrated management, they have been defined by [30]. Regarding the lagging indicators, they have been defined under traditional criteria, such as those shown in Tables 2 and 3.

In addition, it is necessary to indicate that these indicators are defined to allow dynamic analysis of risks. For this, the dynamic approach [9] has been considered. Thus, the accident analysis and probability update are two steps that represent the key to dynamic risk assessment. For this, it is necessary to analyze the data in real time so that the probabilities of the events can be calculated and updated following an iterative procedure, which reflects the changes in real time in the system.

An integrated view of this case study with the concepts shown in Figures 1 and 2 can be seen in Figure 4. Thus, in the said figure the lagging indicators (red arrows) are class I (Safety) indicators, that is, they are retrospective indicators. As for the leading indicators (green arrows), they are class II (Risk) indicators, that is, they are predictive. Regarding the integrated management indicators category, their function is to modulate dynamically the corrective and preventive measures linked to the values adopted by the indicators over time. Thus, in general, it will not be necessary to apply measures when the percentages relative to the leading indicators are within the established specifications, that is when the associated risk can be considered low or tolerable, according to the risk assessment technique applied in each specific case (For guidance purposes, this risk level will be the result of combining a low probability with low consequences). Equivalently, it will be necessary to apply measures when the percentages exceed the established specifications, that is, when the associated risk can be considered medium/high or not tolerable (also with guidance purposes, in this case, the risk level will be the result of combining a medium/high probability with medium/high consequences).

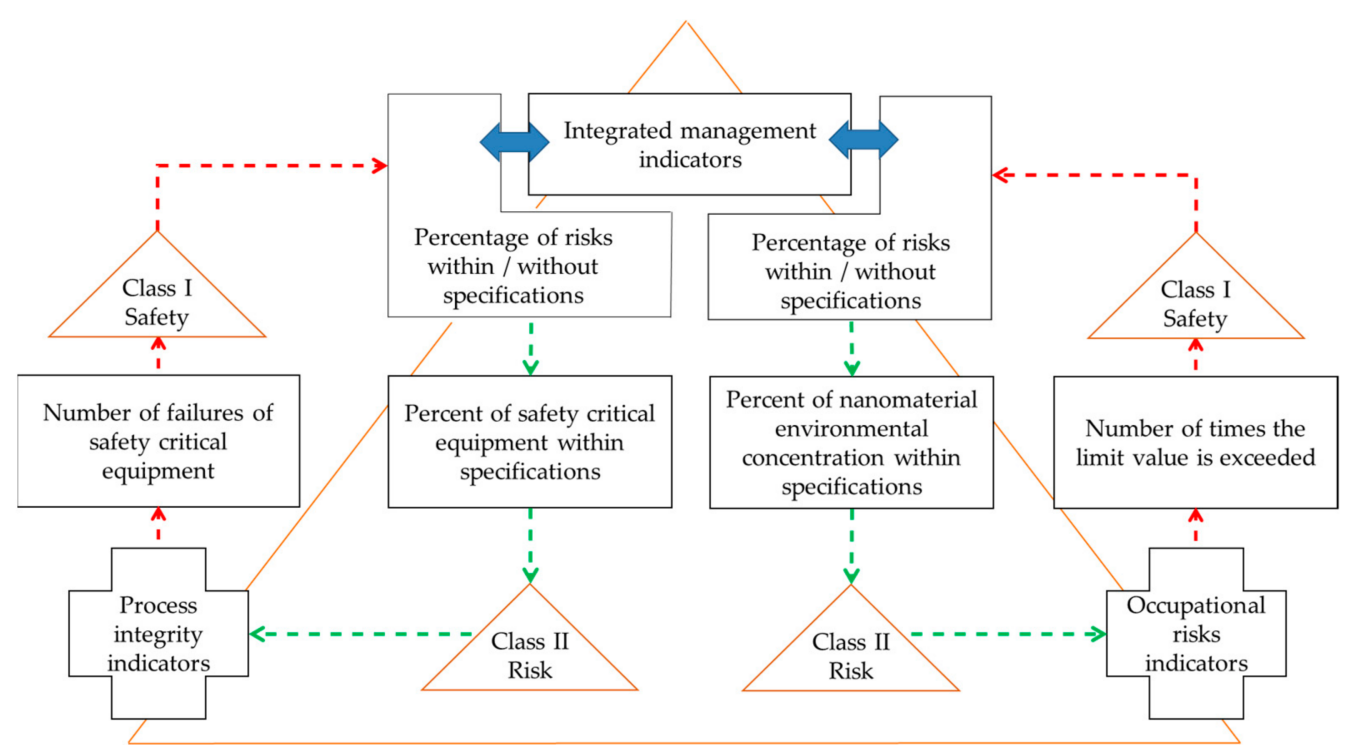

Figure 4. Case study: Integration of leading and lagging indicators in an IMS (Own elaboration).

\section{Discussion and Conclusions}

The objective of this work, which consists of identifying and classifying leading indicators that facilitate dynamic analysis of emerging risks in an IMS, has been achieved through the design of a theoretical framework and its application to a case study.

Such theoretical framework, has been obtained from a bibliographic analysis that presents at least three limitations. Firstly, this theoretical framework has been designed in a schematic and conceptual. Secondly, the initial reference works, as well as the keywords used, conditions, or biases the results obtained towards safety management systems. In this 
regard, the results are strongly influenced by $[2,5,7,27,31]$. Thirdly, the IMS considered are mainly based on ISO standards. Thus, this approach could be expanded with a systematic review of the literature that could improve the results obtained.

Regarding the case study, it is adequate to visualize with an approximate and initial character the applicability of the proposed classification. However, this case study has as clear limitations its theoretical and general characteristics.

Moreover, this work has not analyzed the existing problem regarding the distinction between leading and lagging indicators, as discussed, for example, by $[12,13,32,33]$. In this regard this debate demonstrates the need for a theoretical foundation [20]. In any case, it is necessary to distinguish between retrospective and predictive perspectives to develop dynamic risk assessment methodologies by monitoring THO factors [5]. This work has also not analyzed the overlap between occupational accident and major accident, as discussed in works such as $[12,18]$. Such needs are especially relevant when risks are emerging. About it, the classification of indicators proposed in Table 5 has been qualitatively graded in a very approximate way as a function of the combination of the direction of the leading indicators as well as of the potential associated consequences. This graduation could be interesting to calibrate considering, in addition, other variables, such as the uncertainty variable studied in [31]. The combination of the consequence and the uncertainty variables associated to indicators could improve said graduation and facilitate the definition of approaches for the development of leading indicators.

As a main conclusion and proposals for future works, the conceptual scheme proposed in this work on the classification of the leading indicator represents the first step towards a more in-depth and detailed development that allows the identification and definition of specific leading indicators within an IMS from a dynamic and emerging risk perspective following for it a sufficiently solid methodology. Thus, the characteristics of these leading indicators should allow two types of integration. On the one hand, the integration of these indicators in the common procedures of an IMS, such as the procedures on preventive and corrective action or record control. Furthermore, these indicators should be integrated into the dynamic analysis of emerging risk methodologies Regarding the case study, its generic and theoretical characteristics allow it to be expanded and adapted to real manufacturing processes through future work. As part of this adaptation, the models for the dynamic analysis of the emerging risk applicable to each specific case must be defined, which must include, together with the leading indicators, the specifications regarding the tolerability of the risk.

Author Contributions: Conceptualization, F.B.F., A.S.-L., J.L.F.-B., M.Á.S. and C.G.-G.; Investigation, F.B.F., M.Á.S. and C.G.-G.; Methodology, F.B.F., C.G.-G.; Supervision, F.B.F., A.S.-L., J.L.F.-B., M.Á.S. and C.G.-G.; Writing—original draft, F.B.F., M.Á.S. and C.G.-G.; Writing—review and editing, F.B.F., A.S.-L., J.L.F.-B., M.Á.S. and C.G.-G. All authors have read and agreed to the published version of the manuscript.

Funding: This work was funded by the ETSII-Universidad Nacional de Educación a Distancia (UNED) of Spain, and the Spanish Ministry of Economy and Competitiveness, with the title: "Analysis and Assessment of technological requirements for the design of a New and Emerging Risks standardized management SYStem (A2NERSYS)" with reference DPI2016-79824-R.

Informed Consent Statement: Not applicable.

Conflicts of Interest: The authors declare no conflict of interest.

\section{References}

1. Ramos, D.; Afonso, P.; Rodrigues, M.A. Integrated management systems as a key facilitator of occupa-tional health and safety risk management: A case study in a medium sized waste management firm. J. Clean. Prod. 2020, 262, 121346. [CrossRef]

2. Brocal, F.; González-Gaya, C.; Sebastián, M.A.; Reniers, G.; Paltrinieri, N. Emerging risk management versus traditional risk: Differences and challenges in the context of occupational health and safety. In Proceedings of the 29th European Safety and Reliability Conference, Hannover, Germany, 22-26 September 2019; p. 2889. 
3. Ancione, G.; Paltrinieri, N.; Milazzo, M.F. 2020 Integrating Real-Time Monitoring Data in Risk Assessment for Crane Related Offshore Operations. J. Mar. Sci. Eng. 2020, 8, 532. [CrossRef]

4. Asociación Española de Normalización y Certificación. Management Systems. Guide for the Integration of Management Systems UNE 66177:2005; AENOR: Madrid, Spain, 2005.

5. Paltrinieri, N.; Landucci, G.; Nelson, W.R.; Hauge, S. Proactive Approaches of Dynamic Risk Assessment Based on Indicators. In Dynamic Risk Analysis in the Chemical and Petroleum Industry; Paltrinieri, N., Khan, F., Eds.; Elsevier: Oxford, UK, 2016 ; p. 63.

6. Reiman, T.; Pietikäinen, E. Leading indicators of system safety-Monitoring and driving the organizational safety potential. Saf. Sci. 2012, 50, 1993-2000. [CrossRef]

7. Brocal, F.; Sebastián, M.A.; González, C. Theoretical framework for the new and emerging occupational risk modeling and its monitoring through technology lifecycle of industrial processes. Saf. Sci. 2017, 99, 178-186. [CrossRef]

8. Khan, F.; Rathnayaka, S.; Ahmed, S. Methods and models in process safety and risk management: Past, present and future. Process. Saf. Environ. Prot. 2015, 98, 116-147. [CrossRef]

9. Villa, V.; Paltrinieri, N.; Khan, F.; Cozzani, V. Towards dynamic risk analysis: A review of the risk assessment approach and its limitations in the chemical process industry. Saf. Sci. 2016, 89, 77-93. [CrossRef]

10. Scarponi, G.E.; Paltrinieri, N.; Khan, F.; Cozzani, V. Reactive and proactive approaches: Tutorials and example. In Dynamic in Dynamic Risk Analysis in the Chemical and Petroleum Industry; Paltrinieri, N., Khan, F., Eds.; Elsevier: Oxford, UK, 2016 ; p. 75.

11. Scarponi, G.E.; Paltrinieri, N. Comparison and Complementarity between Reactive and Proactive Approaches. In Dynamic Risk Analysis in the Chemical and Petroleum Industry; Paltrinieri, N., Khan, F., Eds.; Elsevier: Oxford, UK, 2016; p. 93.

12. Swuste, P.; Theunissen, J.; Schmitz, P.; Reniers, G.; Blokland, P. Process safety indicators, a review of literature. J. Loss Prev. Process. Ind. 2016, 40, 162-173. [CrossRef]

13. Ale, B. More thinking about process safety indicators. Saf. Sci. 2009, 47, 470-471. [CrossRef]

14. Ferreira Rebelo, M.; Santos, G.; Silva, R. Integration of management systems: Towards a sustained success and development of organizations. J. Clean. Prod. 2016, 127, 96-111. [CrossRef]

15. Simon, A.; Karapetrovic, S.; Casadesus, M. Evolution of Integrated Management Systems in Spanish firms. J. Clean. Prod. 2012, 23, 8-19. [CrossRef]

16. Bernardo, M.; Casadesus, M.; Karapetrovic, S.; Heras, I. How integrated are environmental, quality and other standardized management systems? An empirical study. J. Clean. Prod. 2009, 17, 742-750. [CrossRef]

17. Sui, Y.; Ding, R.; Wang, H. An integrated management system for occupational health and safety and environment in an operating nuclear power plant in East China and its management information system. J. Clean. Prod. 2018, 183, 261-271. [CrossRef]

18. Brocal, F.; González, C.; Reniers, G.; Cozzani, V.; Sebastián, M.A. Risk Management of Hazardous Materials in Manufacturing Processes: Links and Transitional Spaces between Occupational Accidents and Major Accidents. Materials 2018, 11, 1915. [CrossRef]

19. Barbosa, C.; Azebedo, R.; Rodrigues, M.A. Occupational safety and health performance indicators in SMEs: A literature review. Work 2019, 64, 217-227. [CrossRef]

20. Øien, K.; Utne, I.B.; Herrera, I.A. Building Safety indicators: Part 1-Theoretical foundation. Saf. Sci. 2011, 49, 148-161. [CrossRef]

21. Center for Chemical Process Safety. Guidelines for Chemical Process Quantitative Risk Analysis; American Institute of Chemical Engineers: New York, NY, USA, 2000.

22. Pitblado, R.; Bain, B.; Falck, A.; Litland, K.; Spitzenberger, C. Frequency data and modification factors used in QRA studies. J. Loss Prev. Process. Ind. 2011, 24, 249-258. [CrossRef]

23. Beerens, H.I.; Post, J.G. The use of generic failure frequencies in QRA: The quality and use of failure frequencies and how to bring them up-to-date. J. Hazard. Mater. 2006, 130, 265-270. [CrossRef]

24. API Publication. Risk-Based Inspection Base Resource Document; American Petroleum Institute: Washington, DC, USA, $2000 ;$ p. 581.

25. Pitblado, R.M.; Williams, J.C.; Slater, D.H. Quantitative assessment of process safety programs. Plant/Oper. Prog. 1990, 9, 169-175. [CrossRef]

26. Hauge, S.; Okstad, E.; Paltrinieri, N.; Edwin, N.; Vatn, J.; Bodsberg, L. Handbook for Monitoring of Barrier Status and Associated Risk in the Operational Phase; Norway Center for Integrated Operations in the Petroleum Industry: Trondheim, Norway, 2015.

27. API. Recommended Practice 754 Process Safety Indicators for the Refining and Petrochemical Industries; American Petroleum Institute: Washington, DC, USA, 2010.

28. Brocal, F.; González, C.; Sebastián, M.A. Technique to identify and characterize new and emerging risks: A new tool for application in manufacturing processes. Saf. Sci. 2018, 109, 144-156. [CrossRef]

29. Paltrinieri, N.; Øien, K.; Cozzani, V. Assessment and comparison of two early warning indicator methods in the perspective of prevention of atypical accident scenarios. Reliab. Eng. Syst. Saf. 2012, 108, 21-31. [CrossRef]

30. Amir-Heidari, P.; Maknoon, R.; Taheri, B.; Bazyari, M. A new framework for HSE performance measurement and monitoring. Saf. Sci. 2017, 100, 157-167. [CrossRef]

31. Brocal, F.; Platrinieri, N.; González-Gaya, C.; Sebastian, M.A.; Reniers, G. Approach to the selection of strategies for emerging risk management considering uncertainty as the main decision variable in occupational contexts. Saf. Sci. 2021, $134,105041$. [CrossRef]

32. Hale, A. Why safety performance indicators? Saf. Sci. 2009, 47, 479-480. [CrossRef]

33. Sinelnikov, S.; Inouye, J.; Kerper, S. Inouye, using leading indicators to measure occupational health and safety performance. Saf. Sci. 2015, 72, 240-248. [CrossRef] 